\title{
Heterotopic fundic and pyloric-type gastric mucosa in the rectum presented as a foveolar hyperplastic polyp
}

\author{
Yukihiro Nakanishi ${ }^{1,2}$, Gloria Merenda ${ }^{3}$ \\ 1. Department of Pathology, St. Louis University School of Medicine, St. Louis, Missouri, USA. 2. Department of Pathology, \\ Tulane University School of Medicine, New Orleans, Louisiana, USA. 3. Department of Pathology, St. Mary Hospital, St. \\ Louis, Missouri, USA.
}

Correspondence: Yukihiro Nakanishi. Address: Department of Pathology and Laboratory Medicine, School of Medicine, Tulane University, 1430 Tulane Avenue, SL-79, New Orleans, Louisiana 70112, USA. E-mail: ynakanis@tulane.edu

Received: November 3, 2014

Accepted: December 14, 2014

Online Published: December 18, 2014

DOI : $10.5430 /$ crcp.v2n2p47

URL: http://dx.doi.org/10.5430/crcp.v2n2p47

\begin{abstract}
Heterotopic gastric mucosa has been identified in all levels of the gastrointestinal (GI) tract. However, the finding of heterotopic gastric mucosa in the rectum is rare. We report a rare case of a 48-year old male with heterotopic fundic and pyloric-type gastric mucosa in the rectum incidentally found by sigmoidoscopy. A sessile polyp measuring $1.3 \mathrm{~cm}$ in diameter is surrounded by whitish discolored area measuring $3.0 \mathrm{~cm}$ in diameter. Histologic examination of the biopsy from the whitish discolored area demonstrated fragments of rectal mucosa with heterotopic fundic and pyloric-type gastric mucosa, whereas histologic examination of the biopsy from the rectal polyp showed fragments of heterotopic pyloric-type gastric mucosa with foveolar hyperplasia, which can explain the polypoid appearance. No intestinal metaplasia or Helicobacter pylori are identified. Our case is unique in that the lesion appeared as a polyp due to the foveolar hyperplasia.
\end{abstract}

\section{Key words}

Heterotopic fundic and pyloric-type gastric mucosa, Rectum, Histopathology, Foveolar hyperplasia, Polyp

\section{I ntroduction}

Heterotopic gastric mucosa has been identified in all levels of the gastrointestinal (GI) tract. Esophageal heterotopic gastric mucosa and duodenal heterotopic gastric mucosa are relatively common lesions ${ }^{[1,2]}$. However, the finding of heterotopic gastric mucosa in the rectum is rare. Heterotopic gastric mucosa in the rectum is often identified as a rectal polyp ${ }^{[3]}$. There has been no detailed explanation for the formation of polypoid lesion. We report a rare case of an asymptomatic 48-year old male with heterotopic fundic and pyloric-type gastric mucosa in the rectum presented as a foveolar hyperplastic polyp.

\section{Case report}

The patient is an asymptomatic 48-year old male with a medical history of asthma who underwent screening sigmoidoscopy. He had no history of GI diseases. The standard endoscope was advanced to the rectum and sigmoid colon. A sessile polyp measuring $1.3 \mathrm{~cm}$ in diameter was found on the right lateral wall of the distal rectum. The sessile polyp is 
surrounded by whitish discolored area measuring $3.0 \mathrm{~cm}$ in diameter (see Figure 1). Two $3 \mathrm{~mm}$ sessile sigmoid polyps were also found. The ultrasound examination showed a rectal polyp arising from the mucosa. Histologic examination of the biopsy from the whitish discolored area demonstrated fragments of rectal mucosa with heterotopic fundic and pyloric-type gastric mucosa (see Figure 2, 3). Transition from heterotopic gastric mucosa to rectal mucosa with goblet cells was clearly seen. Histologic examination of the biopsy from the rectal polyp showed fragments of heterotopic pyloric-type gastric mucosa with foveolar hyperplasia comprising superficial gastric differentiated cells similar to foveolar epithelium (see Figure 4), which can explain the polypoid appearance. No intestinal metaplasia or Helicobacter pylori are identified.

Figure 1. Sigmoidoscopy showed a sessile polyp measuring $1.3 \mathrm{~cm}$ in diameter on the right lateral wall of the distal rectum. The sessile polyp is surrounded by whitish discolored area measuring $3.0 \mathrm{~cm}$ in diameter.

Figure 2. Low power view of the border between the heterotopic gastric mucosa consisting of pyloric-type gastric mucosa and normal rectal mucosa with goblet cells. (H\&E. Original magnification $40 \times$ ).
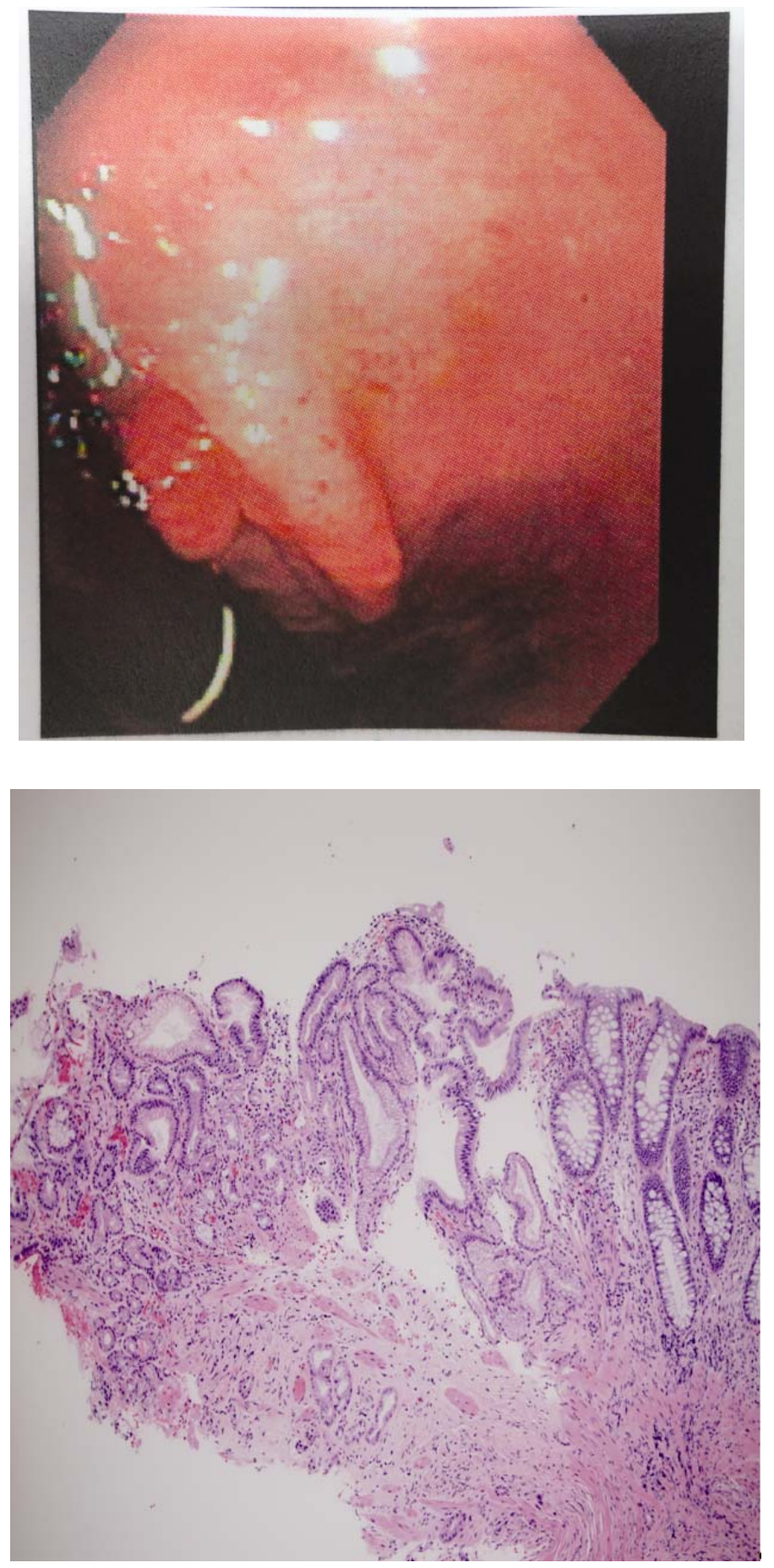

ISSN 2331-2726 E-ISSN 2331-2734 
Figure 3. Low power view of the border between the heterotopic gastric mucosa consisting of fundic-type gastric mucosa and normal rectal mucosa with goblet cells. (H\&E. Original magnification. 100×).
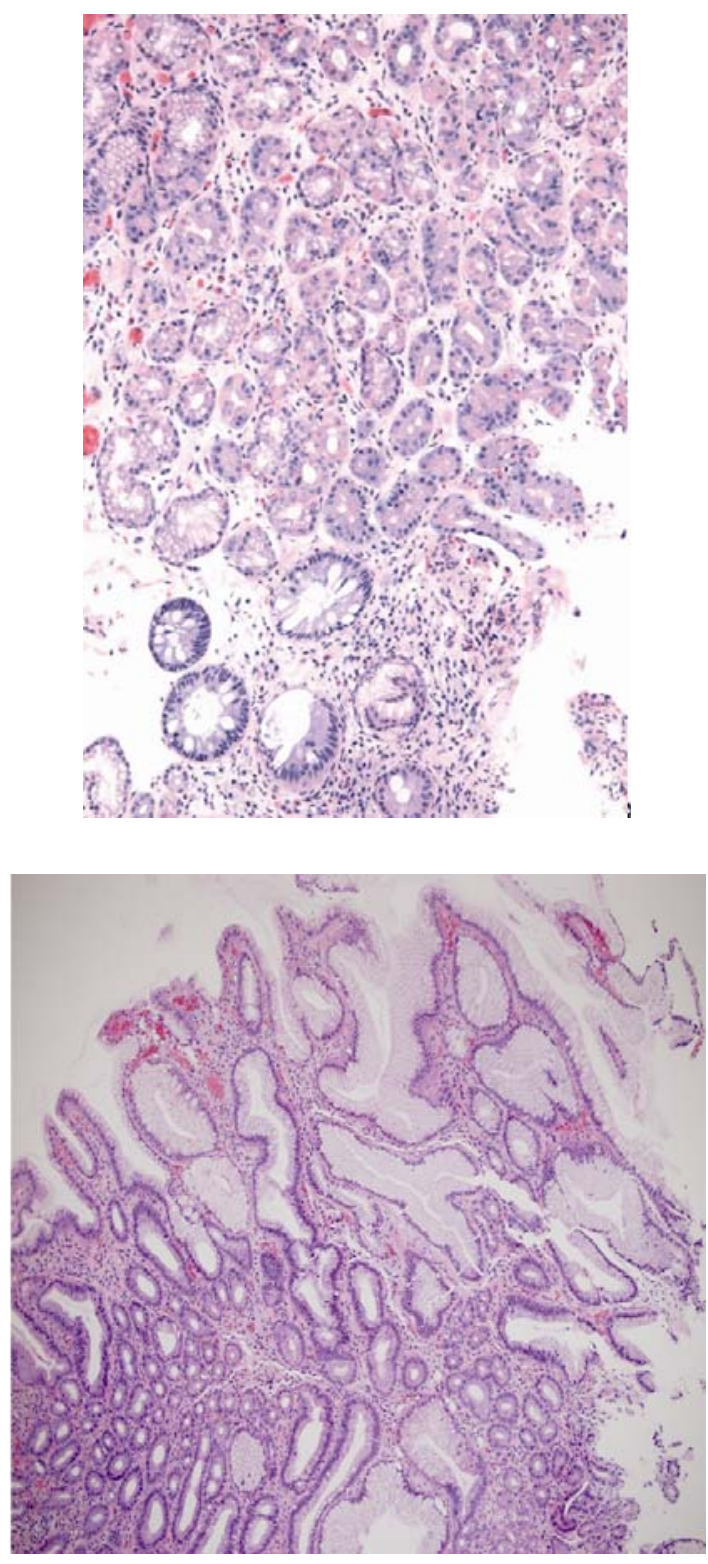

Figure 4. The biopsy from the rectal polyp shows foveolar hyperplasia comprising superficial gastric differentiated cells similar to foveolar epithelium. (H\&E. Original magnification. 40×).

\section{Discussion}

The usual presentations of heterotopic gastric mucosa are rectal bleeding and abdominal pain, with the heterotopic gastric mucosa usually identified on pathologic examination ${ }^{[3]}$. The literature suggests that men are predominantly affected (Male: Female $=20: 7$ ) with a median age of 18 years (range: 6 months to 51 years) ${ }^{[3]}$. Heterotopic gastric mucosa is usually found in the posterolateral wall of the rectum, between $5 \mathrm{~cm}$ and $8 \mathrm{~cm}$ from the anal verge ${ }^{[4]}$. The exact mechanism for the development of heterotopic gastric mucosa in the rectum remains to be seen. Several theories including developmental errors or prior inflammatory reactions have been postulated ${ }^{[3,5]}$. The majority of the reported patients were symptomatic, and complete relief could be obtained following treatment including surgical resection, endoscopic polypectomy or ablation ${ }^{[6]}$. Our patient was asymptomatic, and recommended for follow up without treatment.

Our case is unique in that the lesion appeared as a polyp due to the foveolar hyperplasia. Heterotopic gastric mucosa in the rectum is often identified as a rectal polyp ${ }^{[3]}$. However, there has been no detailed explanation for the formation of polypoid lesion. There are no endoscopically distinctive features of heterotopic gastric mucosa in the rectum, and the 
diagnosis is made only on pathologic examination. In our case the biopsy from the rectal polyp exhibited foveolar hyperplasia, and the biopsy from the whitish discolored area demonstrated heterotopic fundic and pyloric-type gastric mucosa, showing clear correlation between endoscopic features and histopathologic findings. There have been previous reports of Helicobacter pylori infection and the development of adenoma in heterotopic gastric mucosa of the rectum ${ }^{[5,7]}$. The biopsy specimen of current case was negative for Helicobacter pylori, intestinal metaplasia or neoplasm.

\section{Conflict of interests}

The authors have no financial conflict of interests.

\section{Disclaimer}

Presented at the 2011 ASCP annual meeting, Las Vegas, USA, October 19 - 23, 2011.

\section{References}

[1] Yu L, Yang Y, Cui L, et al. Heterotopic gastric mucosa of the gastrointestinal tract: prevalence, histological features, and clinical characteristics. Scand J Gastroenterol. 2014; 49 (2): 138-144. http://dx.doi.org/10.3109/00365521.2013.860558

[2] Terada T. Pathologic observations of the duodenum in 615 consecutive duodenal specimens: I. benign lesions. Int J Clin Exp Pathol. 2012; 5(1): 46-51. PMid: 22295146.

[3] Srinivasan R, Loewenstine H, Mayle JE. Sessile polypoid gastric heterotopias of rectum. Arch Pathol Lab Med. 1999; 123 : 222-224. PMid: 10086510.

[4] Devereaux CE, Devereaux RG. Heterotopic gastric mucosa of the rectum with a review of the literature. J Clin Gatroenterol. 1994; 19: 41-45. http://dx.doi.org/10.1097/00004836-199407000-00011

[5] Vieth M, Kushima R, De Jonge J, et al. Adenoma with gastric differentiation in a heterotopic corpus mucosa in the rectum. Virchows Arch. 2005; 446: 542-545. PMid: 15838648. http://dx.doi.org/10.1007/s00428-005-1242-2

[6] Steele SR, Mullenix PS, martin MJ, et al. Heterotopic gastric mucosa of the anus: a case report and review of the literature. Ann Surg. 2004; 70: 715-719.

[7] Corrigan MA. Shields CJ, Kirwan WO. Immunohistochemical demonstration of Helicobacter pylori in rectal ectopia. Surg Laparosc Endosc Percutan Tech. 2009; 19(4): 146-148. http://dx.doi.org/10.1097/SLE.0b013e3181ae534c 